\title{
A review of adverse cutaneous drug reactions resulting from the use of interferon and ribavirin
}

\author{
Nisha Mistry BSc $\mathrm{MD}^{1 *}$, Jonathan Shapero BSc $\mathrm{MD}^{1 *}$, Richard I Crawford MD FRCPC FAAD ${ }^{1,2}$
}

N Mistry, J Shapero, RI Crawford. A review of adverse cutaneous drug reactions resulting from the use of interferon and ribavirin. Can J Gastroenterol 2009;23(10):677-683.

Drug-induced cutaneous eruptions are named among the most common side effects of many medications. Thus, cutaneous drug eruptions are a common cause of morbidity and mortality, especially in hospital settings. The present article reviews different presentations of druginduced cutaneous eruptions, with a focus on eruptions reported secondary to the use of interferon and ribavirin. Presentations include injection site reactions, psoriasis, eczematous drug reactions, alopecia, sarcoidosis, lupus, fixed drug eruptions, pigmentary changes and lichenoid eruptions. Also reviewed are findings regarding life-threatening systemic drug reactions.

Key Words: Cutaneous; Drug; Eruption; Interferon; Ribavirin

\section{Une analyse des réactions médicamenteuses cutanées indésirables résultant de l'utilisation d'interféron et de ribavirine}

Les éruptions cutanées induites par les médicaments font partie des principaux effets secondaires de nombreux médicaments. C'est pourquoi elles sont souvent responsables de morbidité et de mortalité, notamment en milieu hospitalier. Le présent article analyse diverses présentations d'éruptions cutanées médicamenteuses et s'attarde aux éruptions déclarées après l'utilisation d'interféron et de ribavirine. Les présentations incluaient des réactions au foyer d'injection, un psoriasis, des réactions eczémateuses médicamenteuses, une alopécie, une sarcoïdose, un lupus, une éruption fixe d'origine médicamenteuse, des modifications pigmentaires et des éruptions lichénoïdes. On y analyse également les constatations portant sur les réactions médicamenteuses systémiques mettant la vie en danger.

a medication. A high level of suspicion should be aroused by a history of symmetric eruptions that appear suddenly. This clinical picture, in conjunction with a history of either a new drug started within the preceding six weeks or a drug that has been used intermittently, is strong evidence of an adverse cutaneous drug reaction.

Table 1 outlines the clinical presentations of various adverse cutaneous drug reactions and lists many of the commonly implicated drugs. It is important to acknowledge that these morphological presentations can be accounted for with factors other than drugs. For example, liver disease, in particular hepatitis $\mathrm{C}$, is associated with lichen planus independent of medication use (4). Therefore, it is imperative to correlate the physical findings with the clinical history to help establish the possible causal relationships.

As a rule, any drug that is administered systemically can cause a cutaneous eruption. Most drug eruptions are accounted for by simple exanthems and urticaria, which in one study accounted for $95 \%$ and $5 \%$ of skin reactions, respectively (2). However, drug eruptions are not limited to these common and relatively benign conditions. Adverse cutaneous drug eruptions may be part of a systemic reaction that can be life-threatening. These severe reactions accounted for only approximately $2 \%$ of all adverse cutaneous reactions (5).

Early diagnosis leads to a better outcome; therefore, it is important for every physician to be aware of the clinical features of a severe cutaneous drug reaction. A serious reaction is portended by the presence of bullae, erosions, purpura or exfoliative dermatitis. Other cutaneous features that warn of a potentially severe reaction include involvement of the mucous ferent ways. Therefore, it is often difficult to discern merely by the morphological presentation whether an eruption is due to

\footnotetext{
*Co-first authors. ${ }^{1}$ Department of Dermatology and Skin Science; ${ }^{2}$ Department of Pathology and Laboratory Medicine, University of British

Columbia, Vancouver, British Columbia

Correspondence: Dr Nisha Mistry, Department of Dermatology and Skin Science, University of British Columbia, 835 West

10th Avenue, Vancouver, British Columbia V5Z 4E3. Telephone 604-875-4747, fax 604-873-9919, e-mail nmistry@interchange.ubc.ca

Received for publication November 21, 2008. Accepted December 13, 2008
} 
TABLE 1

Adverse cutaneous drug eruptions: Morphological presentations and commonly implicated drugs.

\begin{tabular}{|c|c|c|}
\hline Clinical presentation & Morphology of lesions & Implicated drugs \\
\hline Exanthematous eruptions & $\begin{array}{l}\text { Symmetrically arranged erythematous macules and papules, } \\
\text { typically starting on the trunk and spreading peripherally }\end{array}$ & $\begin{array}{l}\text { Penicillins, cephalosporins, sulfonamides, anticonvulsants, } \\
\text { antiretrovirals }\end{array}$ \\
\hline Urticaria & Pruritic, transient, edematous erythematous wheals & Penicillin and other antibiotics, opioids, acetylsalicylic acid \\
\hline Pustular eruptions & $\begin{array}{l}\text { Multiple pustules, or an acneiform eruption that can affect } \\
\text { atypical areas (eg, extremities) }\end{array}$ & $\begin{array}{l}\text { Glucocorticoids, isoniazid, lithium, phenytoin (acneiform); } \\
\text { beta-lactam and macrolide antibiotics, calcium channel } \\
\text { blockers (non-acneiform) }\end{array}$ \\
\hline Bullous eruptions & Erythema, skin fragility, blister formation and scarring & $\begin{array}{l}\text { Vancomycin, captopril, furosemide, penicillin, penicillamine, } \\
\text { tetracyclines }\end{array}$ \\
\hline Fixed drug eruption & $\begin{array}{l}\text { A solitary, round violaceous patch evolving into an edematous } \\
\text { plaque and resolving with pigmentation; commonly on the } \\
\text { genitalia or perineum }\end{array}$ & Ibuprofen, naproxen, sulfonamides, tetracyclines \\
\hline Skin necrosis & $\begin{array}{l}\text { Red, painful plaques in fatty areas (breasts, buttocks, hips) that } \\
\text { blister, ulcerate or develop necrosis }\end{array}$ & $\begin{array}{l}\text { Coumadin and heparin (unfractionated and low molecular } \\
\text { weight) }\end{array}$ \\
\hline Lichenoid eruptions & $\begin{array}{l}\text { Scaly, purplish macules and patches evolving into polygonal } \\
\text { papules and plaques }\end{array}$ & Beta-blockers, captopril, thiazides, gold, penicillamine \\
\hline Cutaneous pseudolymphoma & Solitary or widespread violaceous papules, plaques or nodules & Anticonvulsants, antidepressants, antihistamines \\
\hline Vasculitis & Palpable purpura generally found on the lower extremities & $\begin{array}{l}\text { Propylthiouracil, hydralazine, granulocyte colony-stimulating } \\
\text { factor, granulocyte monocyte colony-stimulating factor, } \\
\text { allopurinol, cefaclor, minocycline, penicillamine, phenytoin, } \\
\text { isotretinoin }\end{array}$ \\
\hline
\end{tabular}

membranes, facial swelling and skin tenderness. Systemic symptoms and signs such as fever, lymphadenopathy and arthritis are also strong indicators of a severe reaction that has the potential to include drug-induced hepatitis, nephritis or the involvement of other internal organs (6). In these clinical scenarios, it is vital that the offending agent be identified and discontinued.

Two uncommon but severe drug reactions include StevensJohnson syndrome (SJS) and toxic epidermal necrolysis (TEN). These are life-threatening reactions that lie on a continuum, with mortality rates reaching $30 \%$ (5). As such, it is imperative that clinicians be able to promptly recognize and institute treatment for these severe eruptions.

SJS and TEN are both bullous drug reactions that represent parts of a disease spectrum. SJS is characterized by targetoid skin lesions that induce erosion of less than $10 \%$ of the body surface area (BSA). TEN is characterized by more than $30 \%$ BSA erosion. Any percentage of BSA erosion between 10\% and $30 \%$ is deemed SJS-TEN overlap syndrome. The skin lesions initially present as erythematous macules with epidermal necrosis or purpura at the centres. Any lateral pressure on the intact skin can cause further detachment of the epidermis, a phenomenon known as Nikolsky's sign. Mucous membranes are involved in approximately $90 \%$ of cases with the clinical finding of painful erosions (7).

Treatment involves the immediate withdrawal of the offending drug and the institution of supportive care, ideally in an intensive care unit or a burn unit for individuals more severely affected. This multidisciplinary approach is a key factor in minimizing the morbidity and mortality associated with these two conditions.

\section{CUTANEOUS REACTIONS TO INTERFERON AND RIBAVIRIN}

The use of interferon has been implicated in a variety of cutaneous eruptions. The incidence of cutaneous eruptions has been estimated to be $13 \%$ to $23 \%(8,9)$. Combination therapy with ribavirin has been associated with an increased incidence of adverse cutaneous reactions (10). For the present review, a MEDLINE search was conducted for articles published from January 2000 to August 2008, under the headings "interferon/ adverse effects" or "ribavirin/adverse effects". This search yielded 2599 results. These 2599 results were then manually reviewed for studies detailing dermatological findings.

\section{Injection site reaction}

Localized reactions near injection sites are very common, and are estimated to occur to some degree in the majority of patients treated with interferon (11). The typical clinical presentation is an ill-defined, pruritic, erythematous patch or plaque, localized to the point of administration, generally transient and does not require treatment.

A number of variants have been described. Cutaneous necrosis occurs in less than $4 \%$ (12) of individuals receiving interferon-beta and appears to be less frequent with interferonalpha (13). Management of these lesions typically involves alternating the site of injection and local wound care measures. The lesions typically resolve in one to two months.

Other injection site reactions have been reported as bullous eruptions (14), granulomatous reactions (15), injection site alopecia (16), lupus-like eruptions (17) and embolia cutis medicamentosa (18).

\section{Psoriasis}

Psoriasis (Figure 1) is one of the early cutaneous eruptions recognized with interferon treatment, and was reviewed as early as 1986 by Quesada and Gutterman (19). These cases are not limited to hepatitis $\mathrm{C}$ patients, and have been described in individuals with hepatitis B (20) and chronic myeloid leukemia (21). Since the introduction of combination ribavirin and interferon treatment, there have been four case reports of psoriasis (22-25).

The available treatment options for psoriasis in hepatitis patients are limited because common treatments such as 


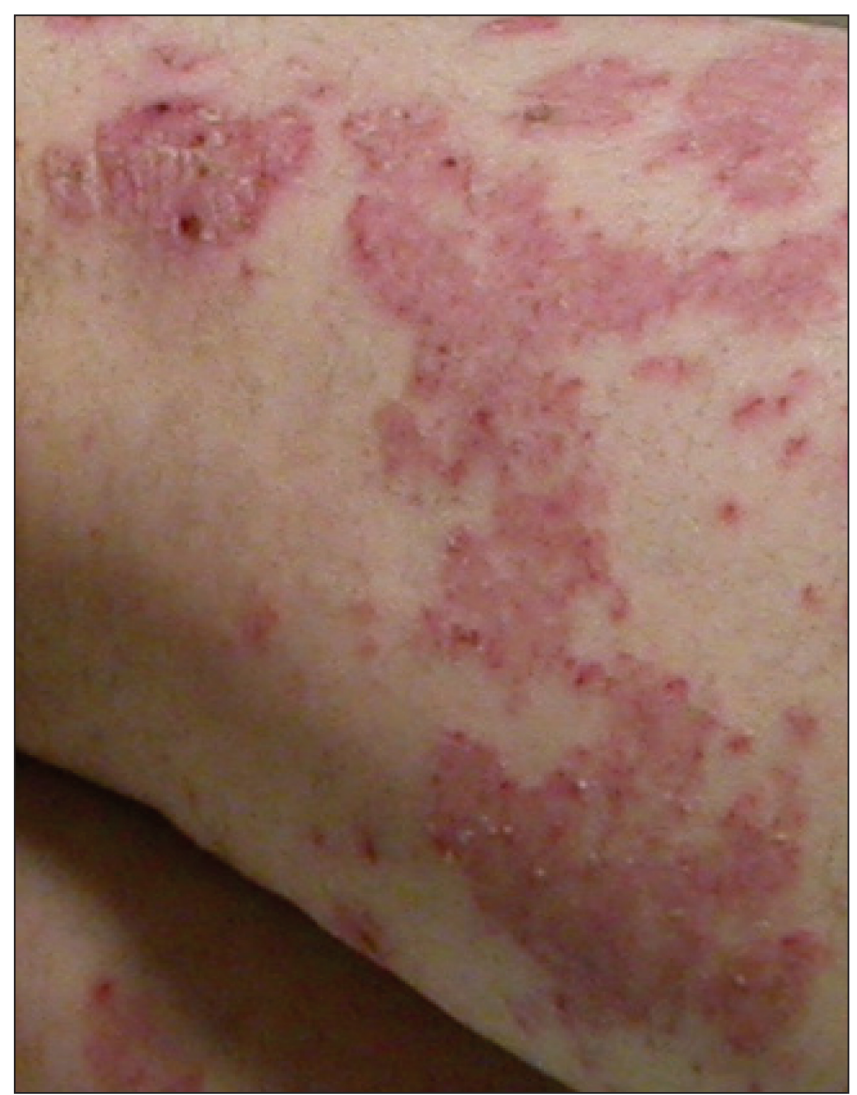

Figure 1) Psoriasis

methotrexate and cyclosporine are contraindicated due to hepatotoxicity. Clobetasol dipropionate $0.05 \%$ ointment or cream has been suggested as a cost-effective choice in Canada. Calcipotriol avoids the potential side effect of corticosteroid atrophy. Calcipotriol may be compounded with clobetasol for additional effect or used as a separate cream or ointment. Additionally, topical anthralin may be used, but it is suggested that anthralin is probably best used with ultraviolet phototherapy in a specialized psoriasis daycare facility because of the potential for staining.

\section{'Eczematoid' drug reaction}

The most commonly reported nonlocal adverse effect is an eczematoid drug reaction, which has been estimated to include $59 \%$ of all noninjection site cutaneous eruptions (8) (Figure 2). Eczematoid drug reactions present as ill-defined clusters of coalescing, erythematous, blanchable, pruritic papules most commonly found on the extremities and trunk. In one early report (26), treatment was discontinued in one-half of the patients with eczematoid eruptions due to severe pruritus. However, Vazquez-Lopez et al (8) found that management with oral hydroxyzine, midpotency topical steroids and emollients allowed for uninterrupted treatment in 14 of 16 affected patients. In the remaining two patients, treatment was discontinued temporarily, then reintroduced with the addition of psychiatric treatment and support.

In most cases, the eruption can be managed without discontinuation or dose reduction of the interferon/ribavirin combination. Topical corticosteroids have been used for decades in hundreds of thousands of patients with systemic viral infections

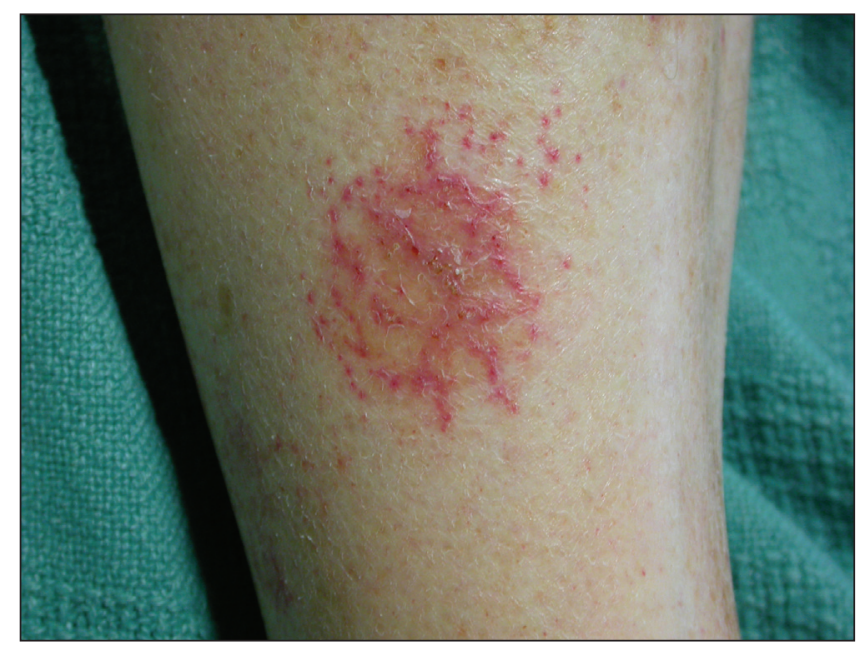

Figure 2) Eczema

such as viral hepatitides and HIV, and there has been no convincing evidence that topical corticosteroids alter the natural history or response to treatment of these infections. Regardless of whether these viral infections are being treated with antiretroviral therapy, their presence is not a contraindication to topical corticosteroids. A cost-effective therapy frequently used in Canada for this type of reaction is $0.1 \%$ betamethasone valerate cream twice daily (avoiding use on the face), with monitoring for the potential side effects of striae and cutaneous atrophy, which are particularly likely to occur within body folds.

If further symptomatic relief from pruritus is desired, this can often be addressed successfully with sedating antihistamines or antipruritic lotions and creams. If pruritus is interfering with sleep, a sedating antihistamine such as diphenhydramine or hydroxyzine at standard doses as tolerated is appropriate. Nonsedating antihistamines are generally of no benefit for the pruritus of eczematoid reactions because they do not cross the blood-brain barrier and, therefore, do not alter the sensation of itch. If pruritus predominates during the daytime, a variety of preformulated lotions and creams containing menthol and camphor, with or without pramoxine, provide immediate but short-term relief without the potential local side effects of higher-potency topical corticosteroids. The application of ice or ice-cold water also provides relief from a localized paroxysm of pruritus. Unlike topical corticosteroids, symptomatic treatment with antihistamines or antipruritics will not alter the appearance or course of the eruption.

In most cases, topical therapies and antihistamines are sufficient to allow the patient to continue therapy with interferon and ribavirin without a dose reduction. If these therapies are maximized, but not sufficiently effective, ultraviolet B phototherapy can be added, which results in a marked reduction of cutaneous inflammation without the use of a systemic immunosuppressant. It can be accessed through dermatologists' offices and hospital physiotherapy departments, but has the inconvenience of twice- or three times-weekly clinic visits. Considering that eczematoid reactions often require repeated or continuous therapy throughout the course of interferon/ribavirin therapy, every effort should be made to avoid systemic immunosuppressants such as prednisone, not 
only because of the immunosuppression but also because of other long-term side effects.

\section{Other eczematous drug reactions}

Meyerson's phenomenon, an eczematous eruption centred around pre-existing melanocytic nevi, was reported in five patients, all of whom had hepatitis $\mathrm{C}$ treated with combination therapy $(27,28)$. Conde-Taboada et al $(27)$ hypothesized that the upregulation of intracellular adhesion molecule (ICAM)-1 is responsible for the eruption. ICAM-1 is stimulated by some interferons and Meyerson's nevi have shown upregulation of ICAM-1 on keratinocytes and dermal endothelial cell surfaces.

Nummular dermatitis, a disorder of intensely pruritic, coinshaped eczematous plaques, was observed in two patients, both of whom were being treated with combination therapy $(29,30)$.

\section{Alopecia}

Hair loss is a frequent adverse effect of interferon treatment and has been reported in 19\% of patients treated with combination interferon and ribavirin (31). These cases typically involve a diffuse thinning of the hair.

Alopecia areata, an autoimmune condition of patchy hair loss, has been described in one patient treated with combination interferon/ribavirin for hepatitis C (32), and in a patient being treated with interferon-alpha for melanoma (33). Alopecia universalis is the most severe variant of alopecia areata in which all scalp and body hair is lost. To date, there have been four case reports of this condition, all of which were in patients who received combination treatment for hepatitis C (34-36). In three of the four cases, the alopecia universalis was reversible on cessation of the interferon treatment.

\section{Other hair changes}

In 1999, Kadayifcilar et al (37) followed 36 patients who were treated with interferon for ocular adverse effects and found trichomegaly of the eyelashes in two patients. Since then, eyebrow and eyelash trichomegaly has been reported in five additional cases (38-42). In one of these cases, the patient was also diagnosed with porphyria cutanea tarda; therefore, the trichomegaly may have been secondary to this condition.

There are single case reports of generalized hypertrichosis (43), hair curling (44) and hair repigmentation associated with interferon treatment (45).

\section{Sarcoidosis}

In 2005, Ramos-Casals et al (46) reported 12 new cases of sarcoidosis associated with hepatitis $\mathrm{C}$ infection, and also found 56 case reports in the literature. Of these 68 cases, 38 presented with predominantly pulmonary disease and 30 with predominantly skin disease. In 50 of these patients, the sarcoidosis was first identified after the initiation of treatment for hepatitis C. In 20 of 50 cases, patients were treated with interferon-alpha alone. The remaining 30 patients were treated with ribavarin and interferon-alpha combination therapy. In the majority of cases ( 33 of 50 ), sarcoidosis was detected within the first six months after the initiation of therapy. Of the above cases, only 21 required treatment. Treatment of most of these cases was with oral corticosteroids. Infliximab was reported to successfully treat interferon-related sarcoidosis in a single case (47). Remission or improvement of sarcoidosis with treatment was described in 38 of the 46 cases in which outcome data were available. Since 2005, there have been numerous additional case reports of sarcoidosis associated with interferon treatment.

Sarcoidosis is not limited to individuals with hepatitic C because it has also been described in melanoma patients treated with interferon-alpha $(48,49)$. Multiple case reports describe sarcoidosis first presenting within a tattoo (50-52). Therefore, the clinician must be attuned to granulomatous changes within a tattoo in patients on interferon treatment. Another clinical presentation has been involvement limited to pre-existing scars (53). A sarcoidosis-like reaction within the lacrimal gland causing orbital swelling has been reported $(54,55)$.

\section{Lupus}

Lupus erythematosus has been reported in four patients treated for hepatitis $C$ (56-59), and also during treatment for multiple sclerosis (60). Lupus panniculitis has also been described in a case of multiple sclerosis (61). Arrue et al (17) found five cases of injection site reactions histologically mimicking lupus in individuals with melanoma and multiple sclerosis. Biopsy specimens demonstrated dermal mucin deposits, dense lymphocytic infiltrates along hair follicles with hydropic degeneration of the follicular basal layer, as seen in lupus. It is therefore reasonable to expect that a number of additional cases that have been diagnosed as simple injection site reactions, would likely demonstrate histological features of this localized lupus-like reaction induced by interferon. The connection between interferon and lupus is perhaps not surprising given that interferoninduced chemokines have been found to be elevated in patients with systemic lupus erythematosus (62). Therefore, exogenous administration of interferon would theoretically stimulate the same enzymes that would cause systemic lupus erythematosus in individuals who would otherwise be unaffected clinically.

\section{Fixed drug eruption}

There have been two reported cases of interferon-associated fixed drug eruptions. One case was in a patient who was treated with combination therapy for hepatitis $\mathrm{C}$ (63). The patient, a 54-year-old man, developed erythematous plaques at the injection sites but also on his forehead and legs. His presentation was initially mistaken for tinea corporis. The other case was a 32-year-old woman being treated with interferon 1-beta for multiple sclerosis (64). In both cases, the lesions resolved on discontinuation of interferon therapy.

\section{Pigmentation disorders}

Simultaneous hyperpigmentation of the tongue and the skin has been reported in three cases $(65,66)$, all of which were in patients with hepatitis $\mathrm{C}$ receiving combination interferon and ribavirin therapy. Two additional cases of tongue hyperpigmentation without associated skin changes have also been reported $(67,68)$.

Vitiligo, a disorder of patchy skin depigmentation, has been reported in a number of patients who were treated for hepatitis $\mathrm{C}$ with combination therapy $(25,69)$. In one case, the vitiligo was segmentally distributed (44).

\section{Lichenoid eruptions}

Various lichenoid eruptions have been described secondary to interferon treatment, all in the setting of hepatitis C. The prototype of these conditions is lichen planus, and this appears 
to be the most commonly reported lichenoid eruption. There have been four case reports of patients on combination therapy, two of which showed predominantly oral involvement (70-74). In one case, the eruption was severe and involved the buccal mucosa, vermilion, scrotum and glans penis. The cutaneous component was successfully treated with prednisone $25 \mathrm{mg}$ daily. The mucosal lesions did not respond, but required tacrolimus $0.03 \%$ solution three times daily to completely resolve. There are also single case reports of linear lichen planus (75), lichen aureus (76) and lichen nitidus (77).

\section{Uncommon cutaneous reactions}

There is a single study reporting three cases of aphthous ulcers (78). All of these cases involved patients being treated with combination therapy for hepatitis C.

There is a single case report (79) of Grover's disease in a patient being treated with interferon and ribavirin. Only ribavirin was discontinued and the lesions resolved, which then recurred on rechallenge. The patient was treated with a 10-day course of $40 \mathrm{mg}$ oral prednisolone, and the lesions completely resolved.

There is a single case report (80) of dermatitis herpetiformis (DH) unmasked by interferon. $\mathrm{DH}$ is an autoimmune blistering disorder that is associated with gluten-sensitive enteropathy. $\mathrm{DH}$ was seen in a 52-year-old woman on combination therapy for hepatitis C. The case was associated with villous atrophy of the duodenum. Although this is an isolated case, there are other reports of gluten-sensitive enteropathy being unmasked by interferon initiation (81).

A case of delusions of parasitosis occurred secondary to interferon in a 49-year-old woman who was treated with combination therapy for hepatitis C (82). Her delusions resolved after discontinuing therapy and recurred on rechallenge.

There is a single case report of pyoderma gangrenosum secondary to interferon treatment (83). Single cases have also been reported for granuloma annulare (84), facial erythema (85), livedo reticularis (86), 'oil cysts' (87), polyarteritis nodosa (88), systemic sclerosis (89), acral sclerosis (90), erythema elevatum diutinum (91), atrophie blanche (92), dermatomyositis (93), scleromyxedema (94), cutaneous mucinosis (95) and immune thrombocytopenic purpura (96).

Leukocytoclastic vasculitis has been reported in three cases (97-99), although this can be observed with hepatitis $\mathrm{C}$ alone; therefore, the cause may be difficult to distinguish.

Rosacea fulminans is a severe form of rosacea with the development of nodules and abscesses; this has been reported in two cases $(100,101)$.

\section{SUMMARY}

The range of skin reactions caused by interferon and ribavirin is quite distinct from those of most other medications. Exceptions are fixed drug eruption and lichenoid eruptions that occur with interferon, ribavirin and many other drugs. Interferon has the unusual but not unexpected property of inducing reactions that resemble nondrug-induced skin diseases. This may be due to an unmasking of a predisposition to diseases such as psoriasis, eczema, lupus, sarcoidosis and alopecia areata because of pro-inflammatory properties.

SJS, TEN and systemic hypersensitivity reactions with cutaneous manifestations have not been reported with interferon alone or with the combination of interferon and ribavirin. Therefore, it is unlikely that interferon and ribavirin would have to be discontinued because of a skin side effect. Rather, the prescribing physician will likely need to be aware of techniques to recognize and manage the specific cutaneous side effects of interferon and ribavirin

ACKNOWLEDGEMENT: The authors thank Dr Gillian de Gannes for contribution of the clinical photographs.

\section{REFERENCES}

1. Vervloet D, Durham S. ABC of allergies: Adverse reactions to drugs. BMJ 1998;316:1511-4.

2. Bigby M, Jick S, Jick H, Arndt K. Drug-induced cutaneous reactions: A report from the Boston Collaborative Drug Surveillance Program on 15,438 consecutive inpatients, 1975 to 1982. JAMA 1986;256:3358-63.

3. Gomes ER, Demoly P. Epidemiology of hypersensitivity drug reactions. Curr Opin Allergy Clin Immunol 2005;5:309-16.

4. Schwaber MJ, Zlotogorski A. Dermatologic manifestations of hepatitis C infection. Int J Dermatol 1997;36:251-4.

5. Wolf R, Orion E, Marcos B, Matz H. Life-threatening acute adverse cutaneous drug reactions. Clin Dermatol 2005;23:171-81.

6. Roujeau JC, Stern RS. Severe adverse cutaneous reactions to drugs. N Eng J Med 1994;331:1272-85.

7. Hazin R, Ibrahimi OA, Hazin MI, Kimyai-Asadi A. StevensJohnson syndrome: Pathogenesis, diagnosis, and management. Ann Med 2008;40:129-38.

8. Vazquez-Lopez F, Manjon-Haces JA, Perez-Alvarez R, Perez-Oliva N. Eczema-like lesions and disruption of therapy in patients treated with interferon-alfa and ribavirin for chronic hepatitis C: The value of an interdisciplinary assessment. Brit J Dermatol 2004;150:1046-7.

9. Kerl K, Negro F, Lubbe J. Cutaneous side-effects of treatment of chronic hepatitis $\mathrm{C}$ by interferon alfa and ribavirin. Brit J Dermatol 2003;149:656.

10. Sookoian S, Neglia V, Castano G, Frider B, Kien MC, Chohuela E. High prevalence of cutaneous reactions to interferon alfa plus ribavirin combination therapy in patients with chronic hepatitis $\mathrm{C}$ virus. Arch Dermatol 1999;135:1000-1.
11. Dalmau J, Pimentel CL, Puig L, Peramiquel L, Roe E, Alomar A. Cutaneous necrosis after injection of polyethylene glycol-modified interferon alfa. J Am Acad Dermatol 2005;53:62-6.

12. Fortuno Y, Marcoval J, Gallego I, Moreno A, Arbizu T, Peyri J. Reacciones cutaneas por interferon beta en una serie de 92 pacientes conesclerosismultiple. MedClin (Barc) 1999;113:447-8.

13. Sasseville D, Ghamdi WA, Khenaizan SA. Interferon-induced cutaneous necrosis. J Cutan Med Surg 1999;3:320-3.

14. Gallina K, Brodell RT, Naffah F, Nedorost S. Local blistering reaction complicating subcutaneous injection of pegylated interferon in a patient with hepatitis C. J Drug Dermatol 2003;2:63-7.

15. Sanders S, Busam K, Tahan SR, Johnson RA, Sachs D. Granulomatous and suppurative dermatitis at interferon alfa injection sites: Report of 2 cases. J Am Acad Dermatol 2002;46:611-6.

16. Lang AM, Norland AM, Schuneman RL, Tope WD. Localized interferon alfa-2b-induced alopecia. Arch Dermatol 1999; 135:1126-8.

17. Arrue I, Saiz A, Ortiz-Romero PL, Rodriguez-Peralto JL. Lupus-like reaction to interferon at the injection site: Report of five cases. J Cutan Pathol 2007;34:18-21.

18. Koontz D, Alshekhlee A. Embolia cutis medicamentosa following interferon beta injection. Mult Scler 2007;13:1203-4.

19. Quesada JR, Gutterman JU. Psoriasis and alpha-interferon. Lancet 1986;1:1466-8.

20. Ketikoglou I, Karatapanis S, Elefsiniotis I, Kafiri G, Moulakakis A. Extensive psoriasis induced by pegylated interferon alpha- $2 \mathrm{~b}$ treatment for chronic hepatitis B. Eur J Dermatol 2005;15:107-9. 
21. Ladoyanni E, Nambi R. Psoriasis exacerbated by interferon-alpha in a patient with chronic myeloid leukemia. J Drug Dermatol 2005; $4: 221-2$.

22. Taylor C, Burns DA, Wiselka MJ. Extensive psoriasis induced by interferon alfa treatment for chronic hepatitis C. Postgrad Med J 2000;76:365-7.

23. Yurci A, Guven K, Torun E, et al. Pyoderma gangrenosum and exacerbation of psoriasis resulting from pegylated interferon alpha and ribavirin treatment of chronic hepatitis C. Eur J Gastroenterol Hepatol 2007;19:811-5.

24. Kartal ED, Colak H, Ozgunes I, Usluer G. Exacerbation of psoriasis due to peginterferon alpha-2b plus ribavirin treatment of chronic active hepatitis C. Chemotherapy 2005;51:167-9.

25. Seckin D, Durusoy C, Sahin S. Concomitant vitiligo and psoriasis in a patient treated with interferon alfa-2a for chronic hepatitis $B$ infection. Pediatr Dermatol 2004;21:577-9.

26. Dereure O, Raison-Peyron N, Larrey D, et al. Diffuse inflammatory lesions in patients treated with interferon alfa and ribavirin for hepatitis C: A series of 20 patients. Brit J Dermatol 2002;147:1142-6.

27. Conde-Taboada A, de la Torre C, Feal C, Mayo E, Gonzalez-Sixto B, Cruces MJ. Meyerson's naevi induced by interferon alfa plus ribavirin combination therapy in hepatitis C infection. Brit J Dermatol 2005;153:1070-2.

28. Girard C, Bessis D, Blatire V, Guilhou JJ, Guillot B. Meyerson's phenomenon induced by interferon-alfa plus ribavirin in hepatitis $\mathrm{C}$ infection. Brit J Dermatol 2005;152:182-3.

29. Shen Y, Pielop J, Hsu S. Generalized nummular eczema secondary to peginterferon Alfa-2b and ribavirin combination therapy for hepatitis C infection. Arch Dermatol 2005;141:102-3.

30. Moore MM, Elpern DJ, Carter DJ. Severe, generalized nummular eczema secondary to interferon alfa- 2 b plus ribavirin combination therapy in a patient with chronic hepatitis $C$ virus infection. Arch Dermatol 2004;140:215-7.

31. Wright M, Forton D, Main J, et al. UK Mild HCV Trial investigators. Treatment of histologically mild hepatitis $\mathrm{C}$ virus infection with interferon and ribavirin: A multicentre randomized controlled trial. J Viral Hepatitis 2008;12:58-66.

32. Agesta N, Zabala R, Diaz-Perez JL. Alopecia areata during interferon alpha-2b/ribavirin therapy. Dermatology 2002;205:300-1.

33. Radny P, Bauer J, Caroli UM, et al. Alopecia areata induced by adjuvant treatment with alpha-interferon in malignant melanoma? Dermatology 2004;209:249-50.

34. Kartal ED, Alpat SN, Ozgunes I, Usluer G. Reversible alopecia universalis secondary to PEG-interferon alpha-2b and ribavirin combination therapy in a patient with chronic hepatitis $C$ virus infection. Euro J Gastroenterol Hepatol 2007;19:817-20.

35. Demirturk N, Aykin N, Demirdal T, Cevik F. Alopecia universalis: A rare side effect seen on chronic hepatitis $C$ treatment with peg-IFN and ribavirin. Eur J Dermatol 2006;16:579-80.

36. Taliani G, Biliotti E, Capanni M, Tozzi A, Bresci S, Pimpinelli N. Reversible alopecia universalis during treatment with PEG-interferon and ribavirin for chronic hepatitis C. J Chemotherapy 2005;17:212-4

37. Kadayifcilar S, Boyacioglu S, Kart H, Gursoy M, Aydin P. Ocular complications with high-dose interferon alpha in chronic active hepatitis. Eye 1999;13:241-6.

38. Ozdogan M, Gur G, Kadayifcilar S, Boyacioglu S, Ozgur O, Teletar H. An unusual adverse effect of interferon: Hypertrichosis of the eyelashes. J Interf Cytok Res 2000;20:633-4.

39. Dikici B, Bosnak M, Dagli A, Haspolat K. Interferon alpha and hypertrichosis of eyelashes. Pediatr Infect Dis J 2002;21:448-9.

40. Goksugur N, Karabay O. Eyelash and eyebrow trichomegaly induced by interferon-alfa 2a. Clin Exp Dermatol 2007;32:583-4.

41. Howaizi M. Pegylated interferon-induced eyelid and eyebrow trichomegaly during chronic hepatitis C. J Gastroenterol Hepatol 2005;20:1945-6.

42. Hernandez-Nunez A, Fernandez-Herrera J, Buceta LR, Garcia-Diez A. Trichomegaly following treatment with interferon alpha-2b. Lancet 2002;359:1107.

43. Misery L. Diffuse hypertrichosis in the course of hepatitis $C$ treatment by IFN-alpha and ribavirin. J Interf Cytok Res 2002;22:881-2.

44. Tinio P, Hadi S, Al-Ghaithi K, Al-Qari H, Rudikoff D. Segmental vitiligo and hair curling after interferon alpha and ribavirin treatment for hepatitis C. Skinmed 2006;5:50-1.

45. Kavak A, Akcan Y, Korkmaz U. Hair repigmentation in a hepatitis C patient treated with interferon and ribavirin. Dermatology 2005;211:171-2.
46. Ramos-Casals M, Mana J, Nardi N, et al. HISPAMEC Study Group. Sarcoidosis in patients with chronic hepatitis $\mathrm{C}$ virus infection: Analysis of 68 cases. Medicine 2005;84:69-80.

47. Menon Y, Cucurull E, Reisin E, Espinoza LR. Interferon-alphaassociated sarcoidosis responsive to infliximab therapy. Am J Med Sci 2004;328:173-5.

48. Pelletier F, Manzoni P, Jacoulet P, Humbert P, Aubin F. Pulmonary and cutaneous sarcoidosis associated with interferon therapy for melanoma. Cutis 2007;80:441-5.

49. Alonso-Perez A, Ballestero-Diez M, Fraga J, Garcia-Diez A, Fernandez-Herrera J. Cutaneous sarcoidosis by interferon therapy in a patient with melanoma. J Eur Acad Dermatol 2006;20:1328-9.

50. Toulemonde A, Quereux G, Dreno B. Sarcoidosis granuloma on a tattoo induced by interferon alpha. Ann Dermatol Vener 2004;131:49-51.

51. Werchniak AE, Cheng SX, Dhar AD, Klaus SN. Sarcoidosis presenting as tattoo changes in a patient undergoing treatment with interferon-alpha and ribavirin. Clin Exp Dermatol 2004;29:547-8.

52. Nawras A, Alsolaiman MM, Mehboob S, Bartholomew C, Maliakkal B. Systemic sarcoidosis presenting as a granulomatous tattoo reaction secondary to interferon-alpha treatment for chronic hepatitis $\mathrm{C}$ and review of the literature. Dig Dis Sci 2002;47:1627-31.

53. Perez-Gala S, Delgado-Jimenez Y, Goiriz R, Fernandez-Herrera J, Fraga J, Garcia-Diez A. Cutaneous sarcoidosis limited to scars following pegylated interferon alfa and ribavirin therapy in a patient with chronic hepatitis C. J Eur Acad Dermatol 2007;21:393-4.

54. Hwang CJ, Gausas RE. Sarcoid-like granulomatous orbital inflammation induced by interferon-alpha treatment. Ophthal Plast Recons 2008;24:311-3.

55. Celik G, Sen E, Ulger AF, et al. Sarcoidosis caused by interferon therapy. Respirology 2005;10:535-40.

56. Ho V, Mclean A, Terry S. Severe systemic lupus erythematosus induced by antiviral treatment for hepatitis C. J Clin Rheumatol 2008; $14: 166-8$.

57. Niewold TB, Swedler WI. Systemic lupus erythematosus arising during interferon-alpha therapy for cryoglobulinemic vasculitis associated with hepatitis C. Clin Rheumatol 2005;24:178-81.

58. Lodato F, Tame MR, Colecchia A. Systemic lupus erythematosus following virological response to peginterferon alfa-2b in a transplanted patient with chronic hepatitis $\mathrm{C}$ recurrence. World J Gastroenterol 2006;12:4253-5.

59. Fukuyama S, Kajiwara E, Suzuki N, Miyazaki N, Sadoshima S, Onoyama K. Systemic lupus erythematosus after alpha-interferon therapy for chronic hepatitis C: A case report and review of the literature. Am J Gastroenterol 2000;95:310-2.

60. Crispin JC, Diaz-Jouanen E. Systemic lupus erythematosus induced by therapy with interferon-beta in a patient with multiple sclerosis. Lupus 2005;14:495-6.

61. Gono T, Matsuda M, Shimojima Y, Kaneko K, Murata H, Ikeda S. Lupus erythematosus profundus (lupus panniculitis) induced by interferon-beta in a multiple sclerosis patient. J Clin Neurosci 2007;14:997-1000.

62. Bauer JW, Baechler EC, Petri M, et al. Elevated serum levels of interferon-regulated chemokines are biomarkers for active human systemic lupus erythematosus. Plos Med 2006;3:e491.

63. Sidhu-Malik NK, Kaplan AL. Multiple fixed drug eruption with interferon/ribavirin combination therapy for hepatitis $\mathrm{C}$ virus infection. J Drugs Dermatol 2003;2:570-3.

64. Tai YJ, Tam M. Fixed drug eruption with interferon-beta-1b. Australas J Dermatol 2005;46:154-7.

65. Gurguta C, Kauer C, Bergholz U, Formann E, Steindl-Munda P, Ferenci P. Tongue and skin hyperpigmentation during PEGinterferon-alpha/ribavirin therapy in dark-skinned non-Caucasian patients with chronic hepatitis C. Am J Gastroenterol 2006;101:197-8.

66. Willems M, Munte K, Vrolijk JM, et al. Hyperpigmentation during interferon-alpha therapy for chronic hepatitis $\mathrm{C}$ virus infection. Brit J Dermatol 2003;149:390-4.

67. Torres HA, Bull L, Arduino RC, Barnett BJ. Tongue hyperpigmentation in a caucasian patient coinfected with HIV and hepatitis $\mathrm{C}$ during peginterferon alfa-2b and ribavirin therapy. Am J Gastroenterol 2007;102:1334-5.

68. Sood A, Midha V, Bansal M, Goyal A, Sharma N. Lingual hyperpigmentation with pegylated interferon and ribavirin therapy in patients with chronic hepatitis C. Ind J Gastroenterol 2006;25:324.

69. Tomasiewicz K, Modrzewska R, Semczuk G. Vitiligo associated with pegylated interferon and ribavirin treatment of patients with chronic hepatitis C: A case report. Adv Ther 2006;23:139-42. 
70. Nagao Y, Kawaguchi T, Ide T, Kumashiro R, Sata M. Exacerbation of oral erosive lichen planus by combination of interferon and ribavirin therapy for chronic hepatitis C. Int J Mol Med 2005; 15:237-41.

71. Guijarro B, Lopez Sanchez AF, Hernandez Vallejo G. Presence of lichen planus during a course of interferon alpha-2a therapy for a viral chronic C hepatitis. Medicina Oral 2001;6:358-63.

72. Varela P, Areias J, Mota F, Canelhas A, Sanches M. Oral lichen planus induced by interferon-alpha-N1 in a patient with hepatitis C. Int J Dermatol 2000;39:239-40.

73. Armour K, Lowe P. Complicated lichenoid drug eruption. Australas J Dermatol 2005;46:21-4.

74. Pinto JM, Marques MS, Correia TE. Lichen planus and leukocytoclastic vasculitis induced by interferon alpha-2b in a subject with HCV-related chronic active hepatitis. J Eur Acad Dermatol 2003;17:193-5.

75. Dominguez MV, Mateu AV, Vieira R, Solano JL, Sintes RN, Salmeron MT. Linear lichen planus and hepatitis C. Dermatol Online J 2006;12:17

76. Gonzalez-Sixto B, Garcia-Doval I, Conde A, et al. Lichen aureus induced by interferon-alpha plus ribavirin. Acta Derm-Venereol 2007;87:87-8.

77. Scheler M, Proelss J, Brauninger W, Bieber T, Wenzel J. Generalized lichen nitidus with involvement of the palms following interferon alpha treatment. Dermatology 2007;215:236-9.

78. Lindahl K, Stahle L, Bruchfeld A, Schvarcz R. High-dose ribavirin in combination with standard dose peginterferon for treatment of patients with chronic hepatitis C. Hepatology 2005;41:275-9.

79. Antunes I, Azevedo F, Mesquita-Guimaraes J, Resende C, Fernandes N, MacEdo G. Grover's disease secondary to ribavirin. Brit J Dermatol 2000;142:1257-8.

80. Borghi-Scoazec G, Merle P, Scoazec JY, Claudy A, Trepo C. Onset of dermatitis herpetiformis after treatment by interferon and ribavirin for chronic hepatitis C. J Hepatol 2004;40:871-2.

81. Cammarota G, Cuoco L, Cianci R, Pandolfi F, Gasbarrini G. Onset of coeliac disease during treatment with interferon for chronic hepatitis C. Lancet 2000;356:1494-5.

82. Robaeys G, De Bie J, Van Ranst M, Buntinx F. An extremely rare case of delusional parasitosis in a chronic hepatitis $\mathrm{C}$ patient during pegylated interferon alpha-2b and ribavirin treatment. World J Gastroenterol 2007;13:2379-80.

83. Yurci A, Guven K, Torun E, et al. Pyoderma gangrenosum and exacerbation of psoriasis resulting from pegylated interferon alpha and ribavirin treatment of chronic hepatitis C. Euro J Gastroenterol Hepatol 2007;19:811-5.

84. Kluger N, Moguelet P, Chaslin-Ferbus D, Khosrotherani K, Aractingi S. Generalized interstitial granuloma annulare induced by pegylated interferon-alpha. Dermatology 2006;213:248-9.

85. Tursen U, Kaya TI, Ikizoglu G. Interferon-alpha 2b induced facial erythema in a woman with chronic hepatitis $\mathrm{C}$ infection. J Eur Acad Dermatol 2002;16:285-6.
86. Ruiz-Genao DP, Garcia-F-Villalta MJ, Hernandez-Nunez A, et al. Livedo reticularis associated with interferon alpha therapy in two melanoma patients. J Eur Acad Dermatol 2005;19:252-4

87. Von Stebut E, Brauninger W. Development of oil cysts after subcutaneous injection of interferon-alpha and interleukin-2. Brit J Dermatol 2006;155:848-9.

88. Dohmen K, Miyamoto Y, Irie K, Takeshita T, Ishibashi H. Manifestation of cutaneous polyarteritis nodosa during interferon therapy for chronic hepatitis $\mathrm{C}$ associated with primary biliary cirrhosis. J Gastroenterol 2000;35:789-93.

89. Tahara H, Kojima A, Hirokawa T, et al. Systemic sclerosis after interferon alphacon-1 therapy for hepatitis C. Intern Med 2007;46:473-6.

90. Saydam G, Bozkurt D, Sahin F, et al. Acral sclerosis due to interferon-alpha-2b in chronic myelogenous leukemia. Acta Haematol-Basel 2002;107:43-5.

91. Gil M, Chizzolini C, Kaya G, Hauser C. Erythema elevatum et diutinum, multiple sclerosis and interferon beta. Dermatology 2004;209:75-6.

92. Bugatti L, Filosa G, Nicolini M, Filosa A, Verdolini R. Atrophie blanche associated with interferon-alfa adjuvant therapy for melanoma: A cutaneous side effect related to the procoagulant activity of interferon? Dermatology 2002;204:154.

93. Dietrich LL, Bridges AJ, Albertini MR. Dermatomyositis after interferon alpha treatment. Med Oncol 2000;17:64-9.

94. Kumar N, Rodriguez M. Scleromyxedema in a patient with multiple sclerosis and monoclonal gammopathy on interferon beta-1a. Mult Scler 2004;10:85-6.

95. Benito-Leon J, Borbujo J, Cortes L. Cutaneous mucinoses complicating interferon beta-1b therapy. Eur Neurol 2002;47:123-4.

96. Dimitroulopoulos D, Dourakis SP, Xinopoulos D, Tsamakidis K, Paraskevas E. Immune thrombocytopenic purpura in a patient treated with interferon alfacon-1. J Viral Hepatitis 2004:11:477-8.

97. Adisen E, Dizbay M, Hizel K, Ilter N. Leukocytoclastic vasculitis during pegylated interferon and ribavirin treatment of hepatitis $\mathrm{C}$ virus infection. Ind J of Dermatol Venereol Leprol 2008;74:60-2.

98. Batisse D, Karmochkine M, Jacquot C, Kazatchkine MD, Weiss L. Sustained exacerbation of cryoglobulinaemia-related vasculitis following treatment of hepatitis $\mathrm{C}$ with peginterferon alfa. Eur J Gastroenterol Hepatol 2004;16:701-3.

99. Pinto JM, Marques MS, Correia TE. Lichen planus and leukocytoclastic vasculitis induced by interferon alpha-2b in a subject with HCV-related chronic active hepatitis. J Eur Acad Dermatol 2003;17:193-5.

100. Jensen SL, Holmes R. Rosacea fulminans associated with pegylated interferon alpha-2B and ribavirin therapy. J Drug Dermatol 2003;2:554-6

101. Bettoli V, Mantovani L, Boccia S, Virgili A. Rosacea fulminans related to pegylated interferon alpha-2b and ribavirin therapy. Acta Derm Venereol 2006;86:258-9. 


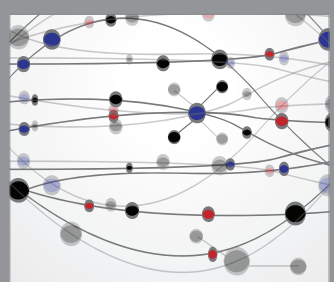

The Scientific World Journal
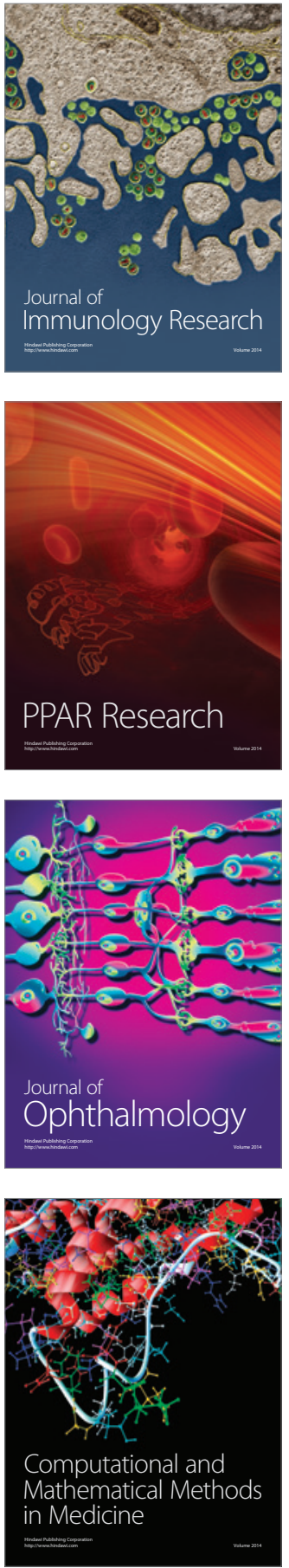



Gastroenterology Research and Practice

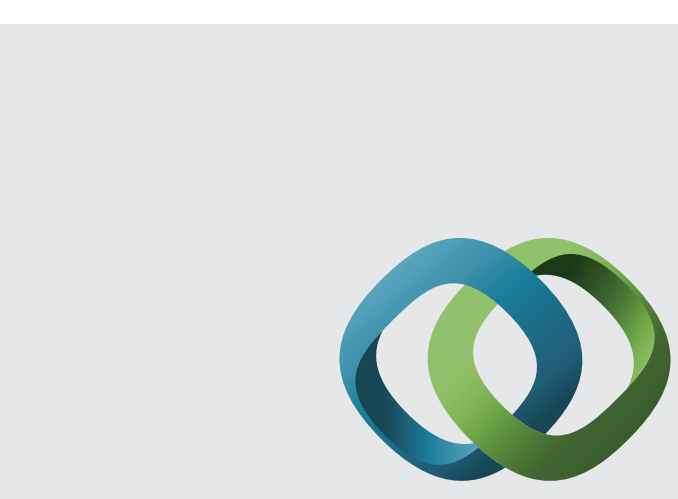

\section{Hindawi}

Submit your manuscripts at

http://www.hindawi.com
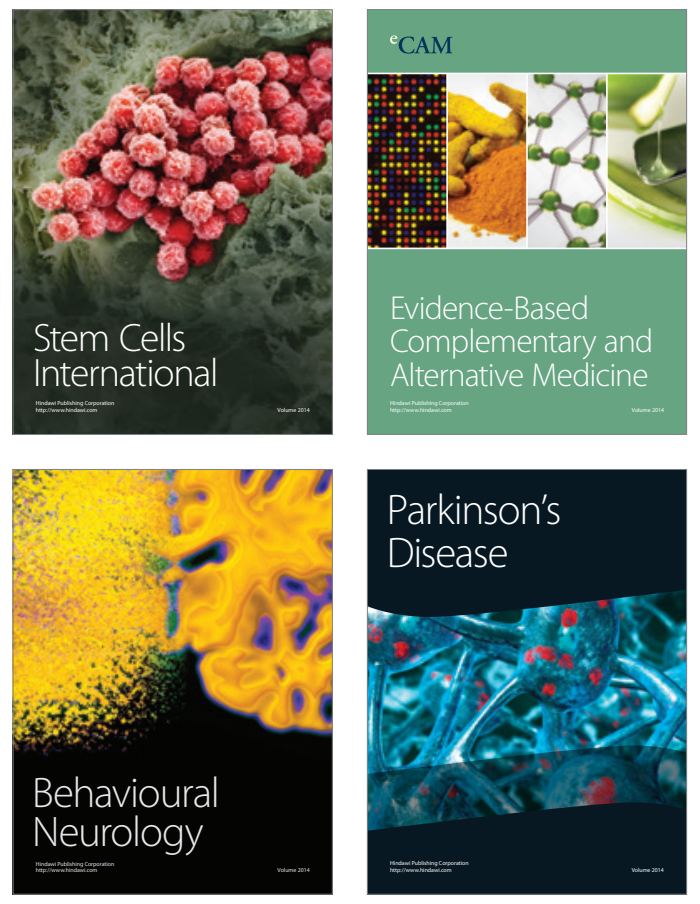
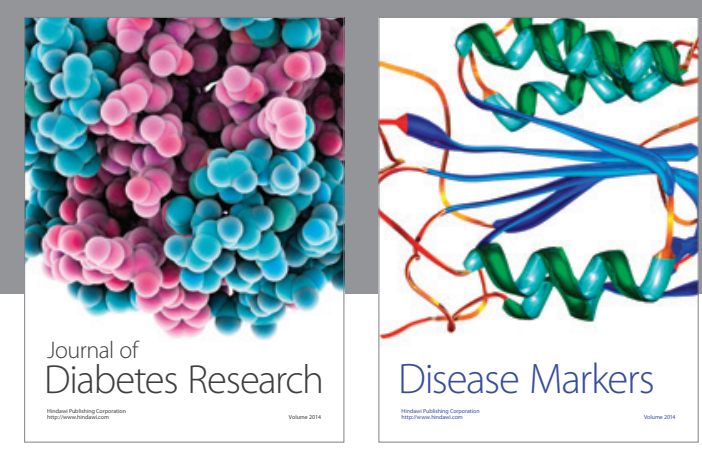

Disease Markers
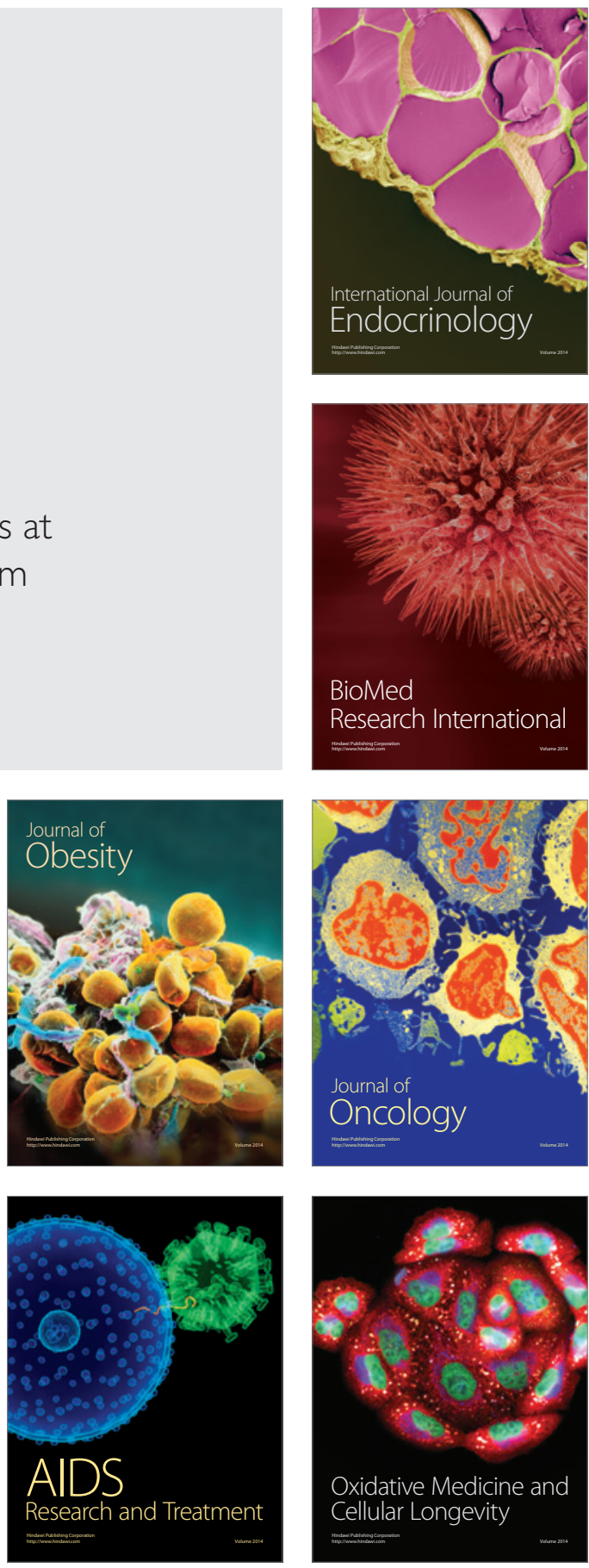